\title{
Organization's Orderly Interest Exploration: Inception, Development and Insights of AIAA's Topics Database
}

\author{
Joseph R Marshall ${ }^{1}$ \\ BAE Systems, Manassas, Virginia, 20110 \\ A. Terry Morris ${ }^{2}$ \\ NASA Langley Research Center, Hampton, Virginia 23681
}

[Abstract] Since 2003, AIAA’s Computer Systems and Software Systems Technical Committees (TCs) have developed a database that aids technical committee management to map technical topics to their members. This Topics/Interest (T/I) database grew out of a collection of charts and spreadsheets maintained by the TCs. Since its inception, the tool has evolved into a multi-dimensional database whose dimensions include the importance, interest and expertise of TC members and whether or not a member and/or a TC is actively involved with the topic. In 2005, the database was expanded to include the TCs in AIAA's Information Systems Group and then expanded further to include all AIAA TCs. It was field tested at an AIAA Technical Activities Committee (TAC) Workshop in early 2006 through live access by over 80 users. Through the use of the topics database, TC and program committee (PC) members can accomplish relevant tasks such as: to identify topic experts (for Aerospace America articles or external contacts), to determine the interest of its members, to identify overlapping topics between diverse TCs and PCs, to guide new member drives and to reveal emerging topics. This paper will describe the origins, inception, initial development, field test and current version of the tool as well as elucidate the benefits and insights gained by using the database to aid the management of various TC functions. Suggestions will be provided to guide future development of the database for the purpose of providing dynamics and system level benefits to AIAA that currently do not exist in any technical organization.

\section{Introduction}

\section{A. Background and Needs of AIAA Technical Committees}

An AIAA Technical Committee is made up of volunteers from various government, industry and academic organizations focused on a subject area applied to aerospace. While each group is different in its operations there are common needs in order for it to be successful and contribute to AIAA and the aerospace industry. Figure 1 shows many events, elements and groups that an AIAA TC is involved with in order to function appropriately. The large circle in the center of Figure 1 represents various forms of communication throughout the organization. At the center of the gray circle are the various emails, meetings and teleconferences held between TC members who are

\footnotetext{
${ }^{1}$ Senior Principal Systems Engineer, Space Systems and Electronics, 9300 Wellington Road, Associate Fellow

${ }^{2}$ Software Manager, Safety-Critical Avionics Systems Branch, Mail Stop 130, AIAA Lifetime Associate Fellow
} 
indicated in the Active TC Membership and Alumni, Emeritus ovals. Specific ovals such as Industry Organizations, Other TCs, and TAC represent other organizations with which the TC interacts. The remaining ovals represent the various products produced by the TCs. These include: the TC Website; conferences; workshops and other projects; position papers, summary articles; guides, practices and standards; industry focus lists and other outputs of the TC for the good of the group or the aerospace community.

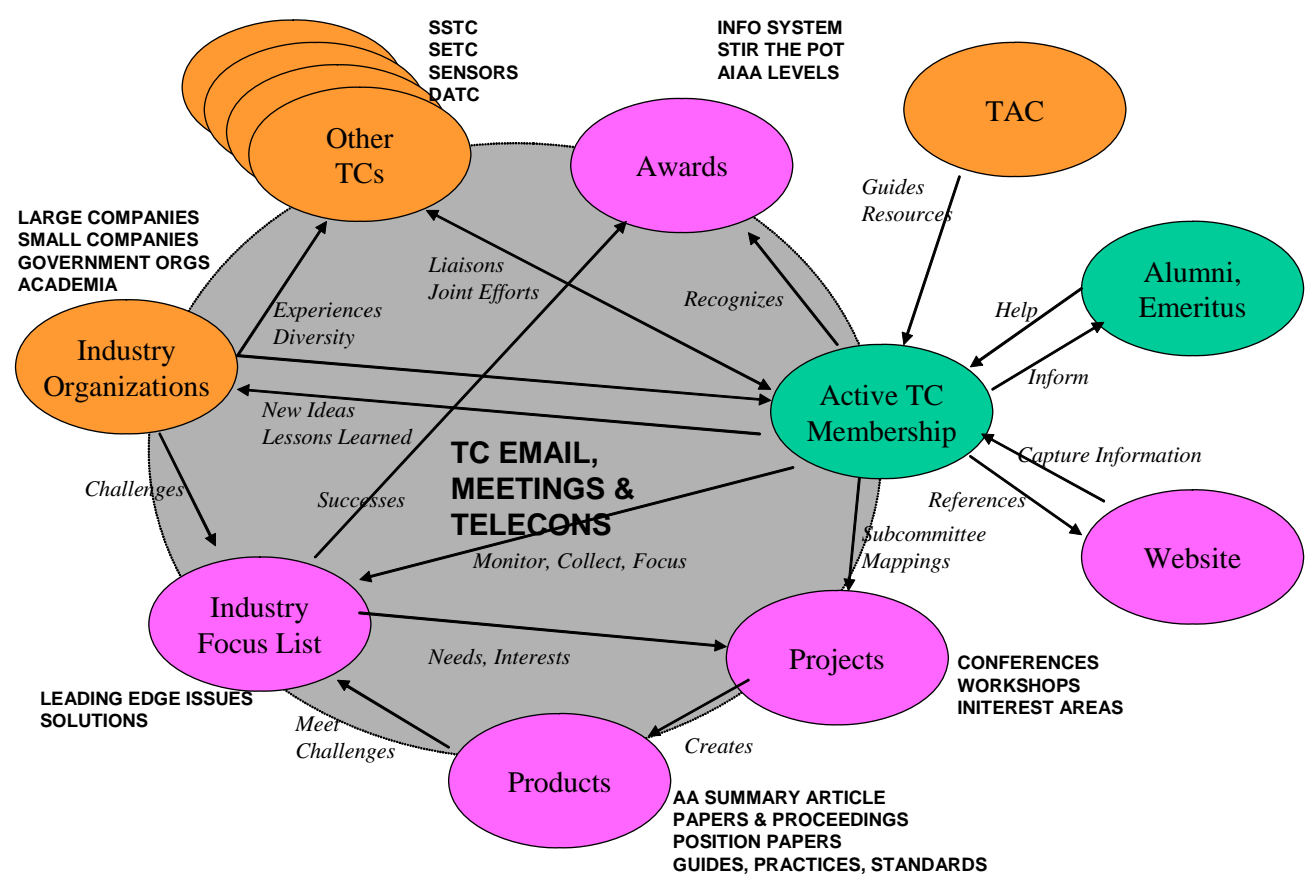

Figure 1. AIAA TC Products and Operations

At the center of all these activities are the topics that define the many technical activities. Topics, from the perspective of TCs, represent the currency by which they do business. Each TC is responsible for a dynamic set of topics (related to their discipline) that change and evolve over time. TCs must manage this information and decide where to focus, where their common interests are and whether there are new topics and information to learn about and distribute to the aerospace community. This paper will explore how these basic needs were handled by the Computer Systems and Software Systems Technical Committees of the AIAA and how the resolution of these needs evolved into the topics database.

\section{Evolution of Topics of Interest}

\section{B. Working Groups of the 1990's}

In the 1990's, technical committees were made up of 35 or more members and with the large number of aerospace organizations during this era, membership was sought after. Most technical committees sponsored one or more conferences or workshops, wrote position papers and articles among their many activities. Internet usage was limited and most everything was done in hardcopy. Often, meeting minutes were mailed to each participant using 
the US Postal Service. The meetings of the TCs were the focus and two or three times a year up to 30 members would gather. These meetings were usually too large to be single track. Much of the time was spent in split groups with each subgroup focused around a topic of interest. Often, the subgroups met outside of the main meetings and worked in their areas of interest. Reports would be generated and presented to the entire group. Topics of interest were maintained through sheer numbers and if a topic had no one interested in it, it would quickly be removed from sub-group status or TC focus.

By the end of the 1990's, mergers, cost savings and other factors cut the real membership of many TCs. Attendance at meetings fell by up to $80 \%$. The Computer Systems TC (CSTC) and Software Systems TC (SSTC) saw such degradation in numbers that they decided to hold their meetings together so as to have critical mass. And those that attended the meetings were seldom as regular. This set the stage for the topics database to emerge as a TC tool.

\section{2000's Era - Smaller Membership, Diverse Interests, Different People}

Meetings in the first few years of the $21^{\text {st }}$ Century at TCs like the CSTC and SSTC typically had 10 people split between the two TCs. Meetings were held single track since there was not enough mass to hold separate meetings. Agendas focused on all the elements in Figure 1, though progress on any one item was slow due to the small number of people present. For many years the Computer Systems and Software Systems TCs were limited to sponsoring a session of papers at someone else's conference and writing a summary article for Aerospace America and maybe working on one long term project. It was during this time that members began to use teleconferences (telecons) to call in during the business part of the meeting when they could not attend. It was also in this time that TCs adapted to lower and varied attendance by starting a monthly one hour telecon to keep working on projects and to assure more constant attention by members. With this infrastructure in place, supplemented by a private website to keep track of projects, minutes and action items, the TCs began to emerge and expand.

Since the subjects and topics of Computer and Software Systems had strong application in aerospace systems, these topics were viewed as enabling technologies for other technical committee disciplines. The special focus of aerospace produced a need to differentiate areas of interest from pure commercial computer and software systems. On top of this, the most value that the TCs could provide would be to focus on those emerging areas and topics that were just being recognized as important to the Aerospace industry or ones that provided the most challenge to the industry. Up until 2003, aerospace topics of interest were tracked very informally. When an article needed to be written for Aerospace America, members designated individuals with specific and clear interests to provide the contribution. Conference sessions and papers were typically few in number and were not focused in an organized way. The papers were drawn primarily from a specific member's interests. As the TCs grew, members were capable of working on more projects and began to sponsor more sessions. In short order, it slowly became obvious that a more disciplined approach was needed to organize the topics of interest in order to make the best use of resources and provide the most value to the members, the AIAA and the aerospace industry. 


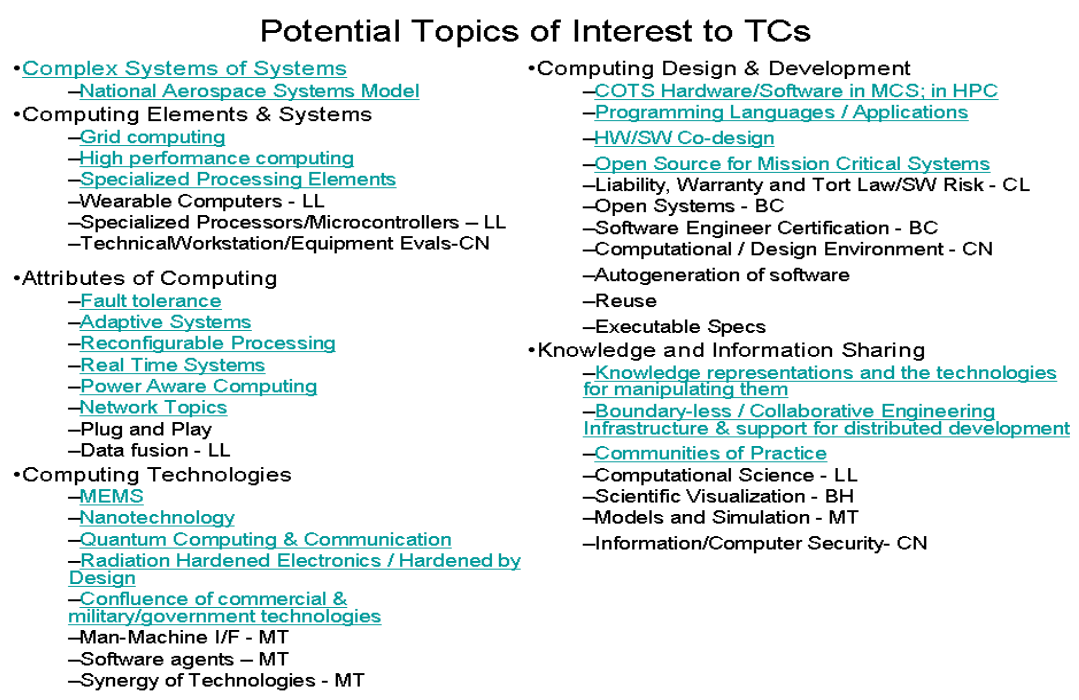

Figure 2. Clustered List of Topics

\section{Working with Lists of Topics}

The disciplined approach to topic organization began with both TCs developing a list of professional interest areas that were relevant to AIAA's Information Systems Group. AIAA clusters all of the TCs into a set of groups with similar characteristics or a thread of commonality. In addition to the Computer and Software Systems TCs, the Information Systems Group (ISG) contains TCs focused in Intelligent Systems, Sensor Systems, Information and Command \& Control Systems, Digital Avionics and Communications Systems. The list of professional areas of interest included: aerospace computing and electronics; controls and displays; embedded systems; high performance computing; information security; nanotechnology; networks; signal processing; software systems; system of systems (SOS) engineering and others. The Computer and Software TCs mapped these areas of interest to the various TCs in the Information Systems Group. This mapping revealed the primary overlap of topics between this cluster of TCs. The Computer and Software Systems TCs then realized that there was a distribution of topics associated with each TC. Areas of overlap between any set of TCs revealed topics with different perspectives depending on each TC. The two TCs began to realize that each TC contains experts in their defined discipline, participated in various conferences of interest and looked for new members according to certain interests. The primary thread that tied these functions together was the topics associated with each TC.

\section{E. Topic Sheets - Formats and Collections}

With this knowledge, both TCs refined their list of topics and began clustering the topics in common themes. After various iterations, the TCs settled on the clustered list of topics shown in Figure 2. With this in hand, it appeared that each TC member had a different view in understanding what each topic represented. To resolve the differing definitions, it was decided that each member would select a topic on the list and develop a quad chart providing basic information on each topic. The quad chart contained a description, a short list of examples, a picture (when supplied) and some reference information that provided more detail on the topic. Three topic chart examples related to COTS hardware/software, high-performance computing and nanotechnology applications are shown in Figure 3. 


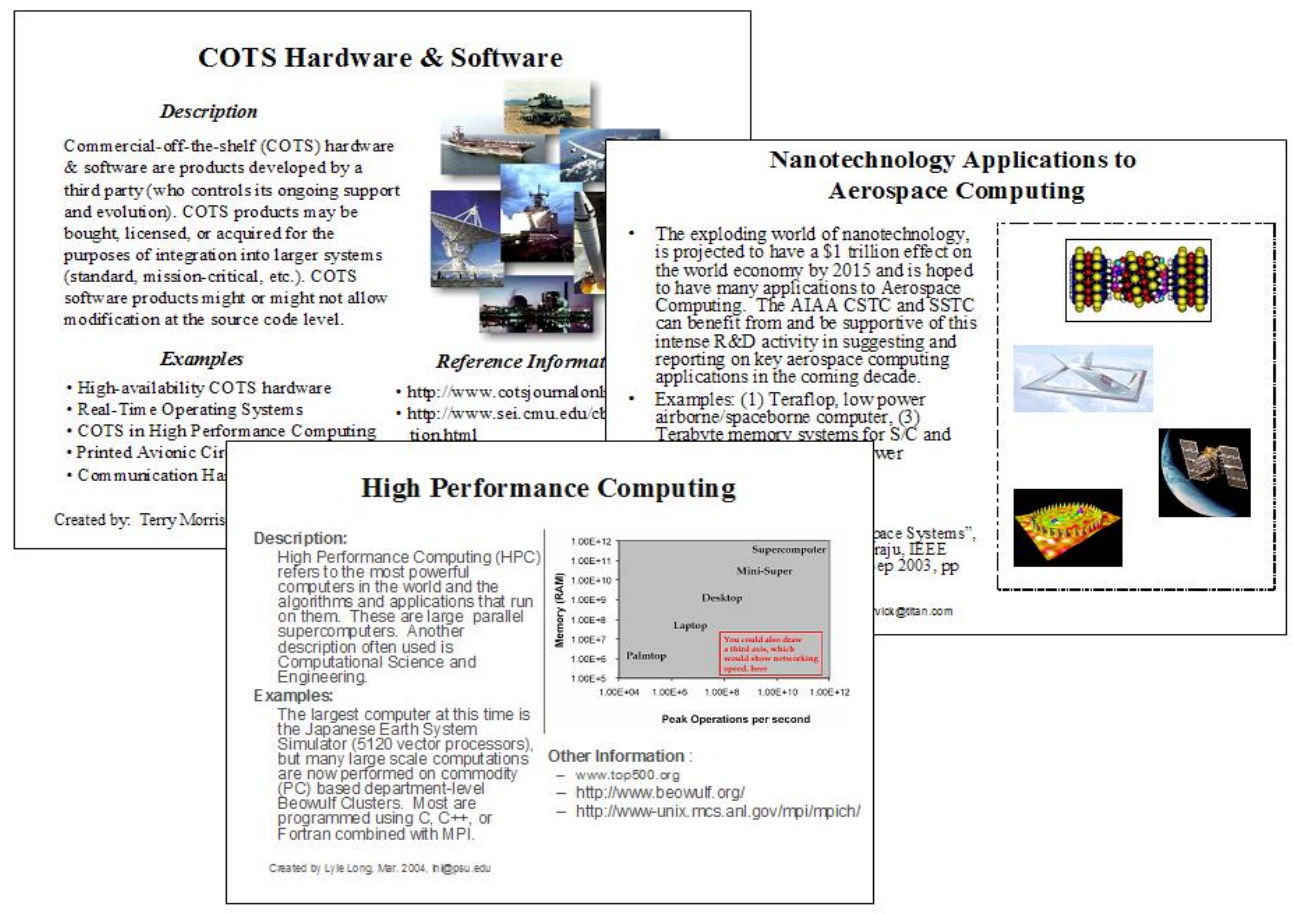

Figure 3. Examples of Topic Charts

\section{F. Topic Spreadsheets for Ratings and their Results}

As each member developed their own topics and began reviewing the topic sheets of others, there emerged the need to identify experts for each topic. Along with topic experts, other dimensions had to be considered such as: level of interest in a topic and whether a member was currently working in a particular topic. The Computer and Software Systems TCs began to rate each topic on these various dimensions with a surprising result. With respect to interests, members from both TCs realized the types of members to recruit and the types of conferences to support. If the expertise for a topic resided in the TC, then that member would be utilized whenever issues revolved around that topic. If there was sufficient interest in a topic and no expert could be found in the TC, then the TC would put forth effort to work with other TCs or groups that worked with the desired topic. The interest ratings also helped to determine topics for each year's Aerospace America article.

\section{G. Use of Topics and Spreadsheets at TC Meetings}

When the Computer and Software Systems TC began searching for conferences to support, the topics spreadsheets describing member interests and expertise proved beneficial. Not only could the members focus on just those topics of interest, the list served as a filter to narrow the field of conferences that were synergistic with the interests of the members. Every now and then, the two TCs would either support or be supported by other AIAA TCs. The topics helped TC members realize the degree of overlap that existed. This is something that was never quantified in any meaningful way. 


\section{TAC Interest from September 2004 to January 2005}

\section{H. SETC, ISTC and Attempts to Expand to ISG}

In late 2004, the Computer Systems and Software Systems TCs realized that their topics of interest overlapped with other TCs and they were finally organized enough to be compared with those of some neighboring TCs. Most of the TCs of interest (Digital Avionics, Sensors, Communications, Intelligent Systems, Command and Control) were within the same AIAA Information Systems Group, since these were all focused on the underlying information systems that were used within the Aerospace Industry though there were a couple outside of ISG (Systems Engineering and Ground Test) also with significant overlap. At the first Infotech Conference (9/2004 in Chicago) and then at the Aerospace Sciences Meeting (ASM) (Reno 1/2005), members of the Computer Systems and Software Systems TC met with some of the other TCs of interest and discussed the topic sheets and ratings and how they might rate the set of existing topic sheets or add ones of interest to their members. This was met with enthusiastic interest that would eventually lead to the AIAA Topics Database.

\section{Reno 2005 - TAC Workshop Goal}

At the same ASM in Reno, there was the annual AIAA Technical Activities Committee (TAC) workshop. This was attended by most TC chairs and others from around the AIAA. One of the recurring themes of the workshop was the increased member value from brainstorming projects that would improve the technical arm of the AIAA. Starting at the conclusion of the workshop and during the week of meetings between TCs, the idea was born to somehow take the topics in front of the TAC Workshop and have them contribute to them or create some similar set of topics for each TC in the AIAA. It was at this point that the topics work of the Computer Systems and Software Systems TC crossed the path of the AIAA New Initiatives Subcommittee (NIS), which is the group responsible for organizing each year's TAC Workshop.

\section{J. Emerging Technologies Tie In}

Also at the ASM, the NIS and its parent organization, the Emerging Technologies Committee (ETC) were struggling with how to identify emerging technologies that the AIAA should pursue. They had created a working list of topics but with no backup or rating. When the topics sheets and ratings database were shown, a subcommittee was formed within the NIS to investigate developing a “deep” database for relating what topic areas each TC and PC were involved with. This database would be significantly more detailed than anything previously attempted within the TAC. It would be based on the topics database previously developed by the Software Systems and Computer Systems TCs.

This database was heralded ${ }^{1}$ as "an invaluable tool to the NIS and the ETC in standing up new TCs and PCs because it would let them know not only who is involved with what, but also to what degree they were involved. It would be useful in identifying synergies between existing groups, useful in upgrading the search engine on the AIAA website and have many other invaluable uses to TAC and the AIAA membership.” 


\section{K. Goal of Workshop}

Over the last six months of 2005, the goals of the workshop were created, debated and finalized. The first goal was to familiarize members with the database, answer questions and work through examples while explaining how to use it. Second, once this familiarity was gained, the participants were to brainstorm on new and innovative uses of the database. Third, capture the human factors concerns of using the database - since many of the TC chairs captured a slice of the general AIAA population, this feedback was expected to be especially useful. Fourth, discuss what the next steps for collecting information, updating the database or enhancing it should be. Fifth, discuss what would be important to maintaining the database. The first three goals focused on the use of the current database while the last two centered on what should happen in the future. In the next chapter of this paper we describe the evolution of the database from the initial Computer Systems and Software Systems topics sheets and Microsoft Excel spreadsheets to the final database that was used at the workshop.

\section{Database Evolution}

\section{Early Prototypes}

Between January and June, several simple prototypes of a potential database were created and worked. All the possible information that would be of interest for a topic was captured and it quickly became obvious that the information would require a relational database. The initial database was created in Microsoft Access since it offered ease of structure for relationships and because it was something that was thought to be expandable for larger usage. After much iteration, a structure was arrived at along with attributes for each parameter. This is illustrated in Figure 4.

At the center of the database are the topic elements. Their only direct parameters are the topic name, its definition and creation date. All other attributes are relational and could have more than one attached to a particular topic. Along the left side of Figure 4 are those attributes that could be directly related. These include keywords, illustrations, examples, web references, publications and products. Each of these has various attributes which are shown in the figure such as dates or definitions. Farther down on the left is the Events parameters which link events such as conferences or workshops to a specific topic. Starting on the lower left and then linked to the lower right are a series of parameters associated with the member or various groups involved in rating a topic. This included structure of groups within groups so that information could be rolled up from members to TCs to Groups to the entire AIAA. At the top center is a structure that would allow topics to relate to topics. This is important as hierarchies of topics are mapped and discovered as an otherwise flat database is too difficult to manage. This would be proven out at the topic workshop.

Along with the structure, an initial set of prototype screen interfaces were created. These were used to work through a usage scenario as well as help size the effort needed to realize the database for production. A list of user actions was defined in order to show the completeness of these screens. Figure 5 shows the total envisioned topic interface with all the parameter fields included. In the top left, the topic's basic properties are entered, that is, the 


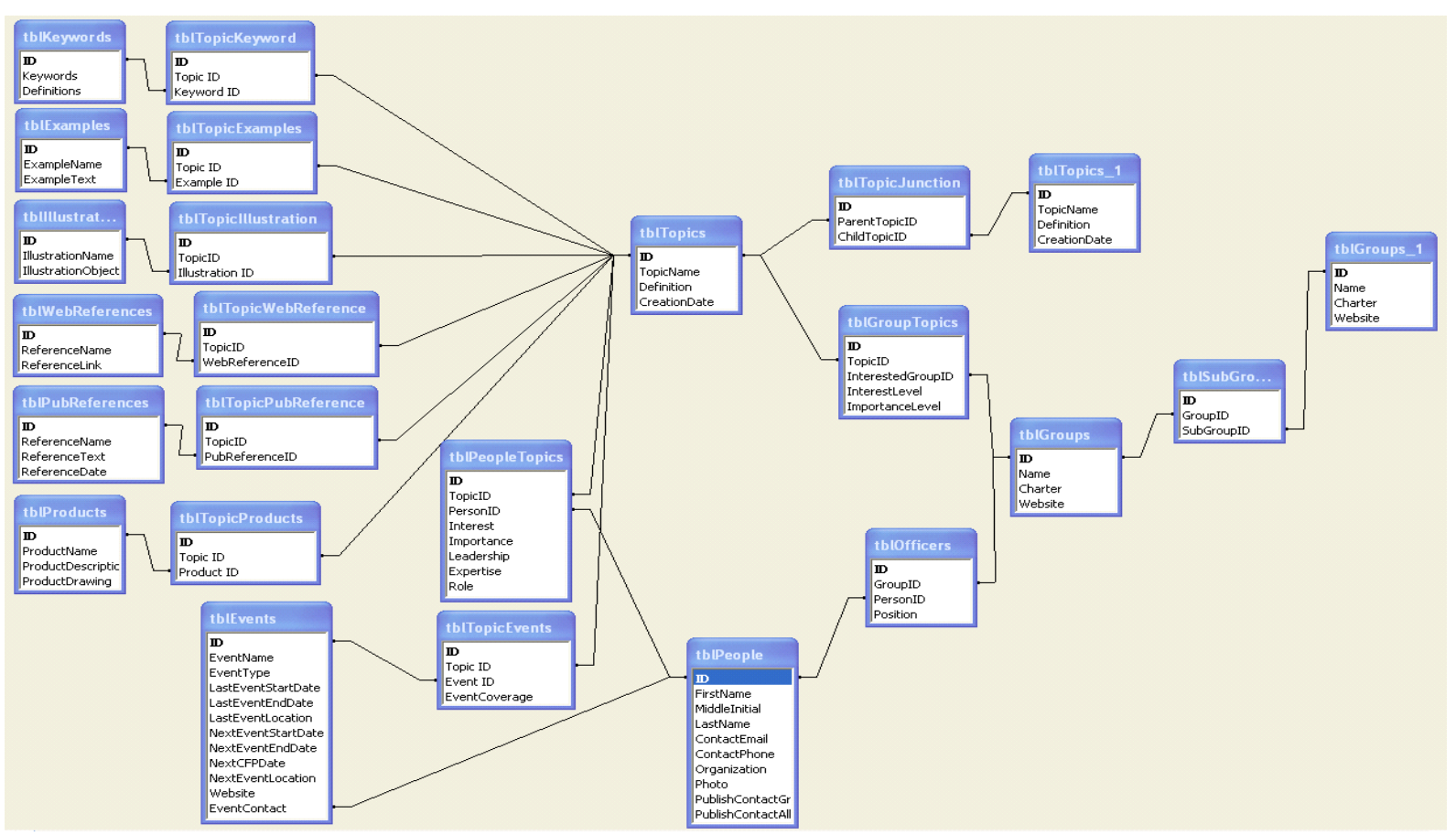

Figure 4. Initial Topics Database Structure Illustrated in MS Access

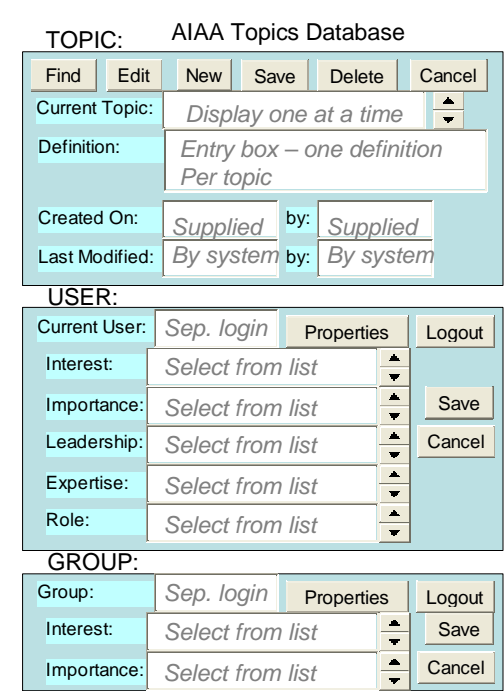

\begin{tabular}{|c|c|c|c|c|c|}
\hline \multicolumn{6}{|c|}{ RELATIONSHIPS: } \\
\hline & & Save & Find & Cancel & \\
\hline \multicolumn{2}{|c|}{ Parent Topics } & \multicolumn{3}{|c|}{ Selected items } & 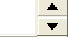 \\
\hline \multicolumn{2}{|c|}{ Child Topics: } & \multicolumn{3}{|c|}{ highlighted } & $\hat{v}$ \\
\hline \multicolumn{6}{|c|}{ ATTRIBUTES: } \\
\hline \multicolumn{2}{|c|}{ Keywords: } & \multirow{2}{*}{\multicolumn{3}{|c|}{$\begin{array}{l}\text { Selected items } \\
\text { highlighted }\end{array}$}} & Save \\
\hline \multicolumn{2}{|c|}{ Edit } & & & & Cancel \\
\hline \multicolumn{2}{|c|}{ Examples: } & \multirow{2}{*}{\multicolumn{3}{|c|}{$\begin{array}{l}\text { Selected items } \\
\text { highlighted }\end{array}$}} & \\
\hline \multicolumn{2}{|l|}{ Edit } & & & & \\
\hline \multicolumn{2}{|c|}{ Illustrations: } & \multirow{2}{*}{\multicolumn{3}{|c|}{$\begin{array}{l}\text { Selected items } \\
\text { highlighted }\end{array}$}} & \\
\hline Edit & $\checkmark$ & & & & \\
\hline Web Ref & & \multirow{2}{*}{\multicolumn{3}{|c|}{$\begin{array}{l}\text { Selected items } \\
\text { highlighted }\end{array}$}} & \\
\hline Edit & 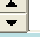 & & & & \\
\hline \multicolumn{2}{|c|}{ Pub Ref's } & \multirow{2}{*}{\multicolumn{3}{|c|}{$\begin{array}{l}\text { Selected items } \\
\text { highlighted }\end{array}$}} & \\
\hline Edit & 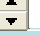 & & & & \\
\hline \multicolumn{2}{|c|}{ Products: } & \multirow{2}{*}{\multicolumn{3}{|c|}{$\begin{array}{l}\text { Selected items } \\
\text { highlighted }\end{array}$}} & \\
\hline Edit & $\checkmark$ & & & & \\
\hline \multicolumn{2}{|l|}{ Events: } & \multirow{2}{*}{\multicolumn{3}{|c|}{$\begin{array}{l}\text { Selected items } \\
\text { highlighted }\end{array}$}} & \\
\hline Edit & $\div$ & & & & \\
\hline
\end{tabular}

Figure 5. Initial Prototype for User / Topic Interaction

name and its definition. In the middle left is the user who is working on the database. He must separately log on and then rate the topic according to various attributes shown. The user's group is shown at the bottom left so this topic information can be connected in case the user is a member of multiple groups. All the potential direct attributes are shown in the main box on the right. The user may add as many attributes as he needs to describe or catalog the topic. The final box in the upper right is for showing relationships between topics. This was the beginning of a system to put hierarchy into the topics. 


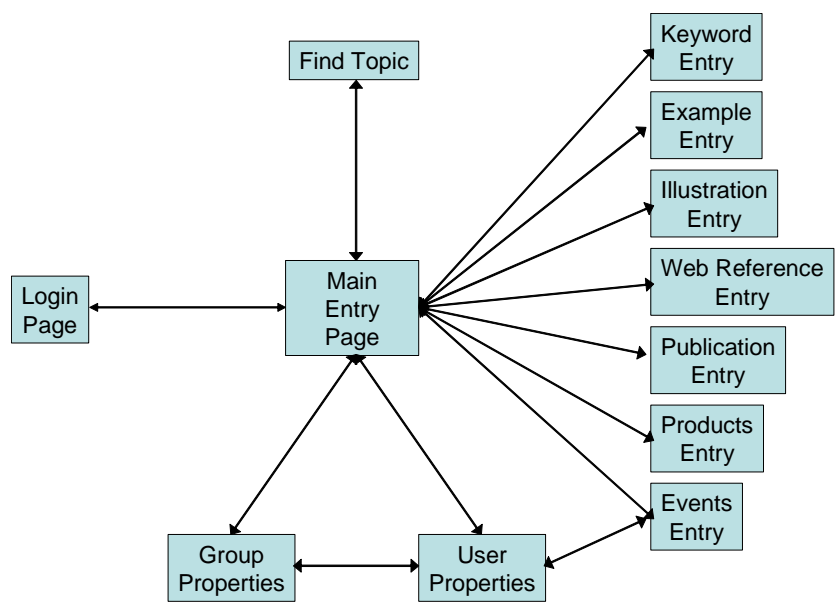

Figure 6. Initial Web Page Relationship Map

\begin{tabular}{|c|c|c|c|c|c|c|}
\hline & & & Dle $P$ & ropertic & $\mathrm{Pag}$ & \\
\hline & Userid & & Sep & login & & \\
\hline New people may be & Photo: & & & & & \\
\hline Added by anyone & Upload & & & & Can & \\
\hline Once a userid / pw & Delete & & & & $\begin{array}{l}\text { Inforn } \\
\text { Visibl }\end{array}$ & $\begin{array}{l}\text { ation } \\
\text { to All }\end{array}$ \\
\hline To a person, only & First $\mathrm{Na}$ & & & Entry & & \\
\hline They can change & Middle & itial: & & Entry & & \\
\hline Their information & Last Na & & & Entry & & \\
\hline & Email: & & ntry & ox & & \\
\hline & Phone: & & ntry & box & & \\
\hline & Organiz & tion: & & intry bo & & \\
\hline & Group: & & layc & ne at a & ime & $\stackrel{-}{*}$ \\
\hline & CMembe & of & & EV & le to & roup \\
\hline & Officer o & Liais & S & lect fro & 7 list & 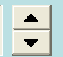 \\
\hline & Proper & & New & & & ancel \\
\hline
\end{tabular}

\section{Figure 7. Initial People Entry Prototype}

This main entry page was envisioned at the center of a set of specific pages to add/edit various attributes for a topic. The initial relationship map is shown in Figure 6. At the top is a search page so that topics already in the database could be located. At the right are data entry pages for each of the attributes where data could be entered. At the bottom are the special entry pages having to do with people, users, groups and their relationships to topics and to events.

Figure 7 shows a second prototype for managing the users of the database. It included the ability to log in to the database, to show group affiliation, and to record personal information such as photos, addresses and emails about the user. It also had the ability to hide some of this information from others who might be using or browsing the database. 
As will be described below, many of the features and user scenarios described by these prototypes would be implemented in the final version while others would be put on the shelf for future updates. With these prototypes in hand, the next step was to get the database implemented so that multiple users could contribute to it.

\section{Ability to Realize as Working Element}

The CSTC, SSTC and other members of the NIS all sought out a person or group to implement this database. Though it was relatively straightforward to describe, as evidenced by the preceding figures, estimates to complete this on a volunteer basis stretched into the next year and would not allow usage for the 2006 TAC Workshop. AIAA TAC leadership realized the potential value and by the summer of 2005 had arranged for AIAA website staff to create the database. This was a fortunate and profound decision and would allow for completion in time for the 2006 TAC Workshop.

\section{N. AIAA Development and Structure of Topic Database}

Once AIAA staff was assigned, a series of meetings took place to describe the envisioned structure to the implementers. The implementers then responded with their vision of what could be created in the time frame and this was played against the potential TAC Workshop Goals. Through this painful process it quickly became evident that many of the attributes to be associated with a topic would have to wait until after 2005.

One significant finding by the web implementers was that the people/groups parameters were already part of the AIAA website and databases. Thus most of those web pages would not be required to have new implementations as the existing structure of member logins and group memberships would be used from the AIAA Website. It was also decided this would allow the database to be seamlessly added to the "My AIAA" section of each member's website experience. The one area that was left in throughout the scenarios was an identification of the user's group membership. Additionally, the tool provided the user with the opportunity to disagree with what membership roles he/she held and to notify AIAA for correction.

The development focused on the input of the topics, their rating by users and their presentation to the users. Getting the data into the database was the driving force as reports could be easily created much closer to the workshop. Due to the wide computer experience of TC Members and the AIAA members in general, making the interface easy to use, intuitive and easy to rate were driving requirements from the NIS. The schedule goal was to have an initial working system in the Fall of 2005 that could be tested by TC Members from the Information Systems Group with time to correct before the TAC Workshop in January 2006.

The initial structure was created and completed to the subcommittee's standards in the late Fall and it was sent out for test among the ISG TC Members. Figure 8 shows the main data entry area for a new generic topic ${ }^{1}$. Note how the topic name, its definitions and keywords are on the same screen as the rating of the topic. The database was pre-seeded with the 37 topics from the Computer Systems and Software Systems Topics sheets. A special report was created that was made available to TC Chairs that showed how many had participated and who had not. Over a three week period, a reasonable number of TC Members used the system and good user feedback was gathered. 


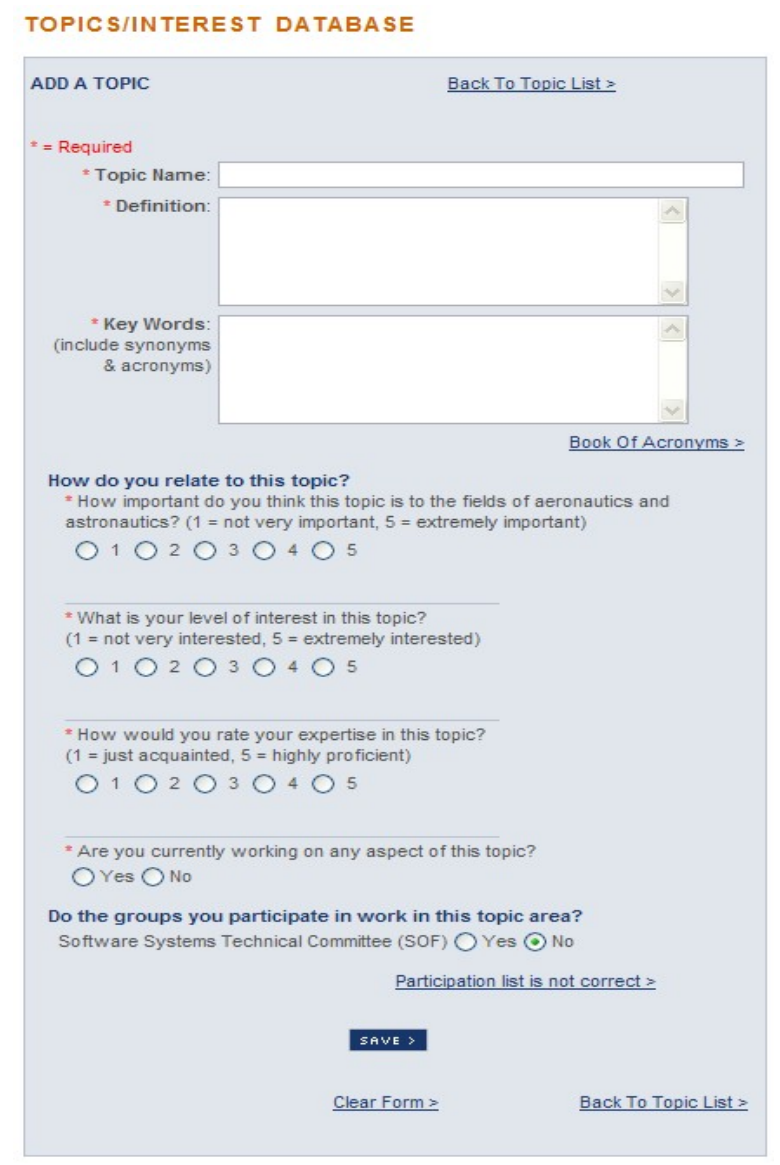

Figure 8. Main Topic Entry Web Page ${ }^{1}$

The database was rated easy to use by most users and most users were able to follow directions. Most of the 37 topics were rated by most of the users. However, a surprising thing happened - there were very few new topics introduced by members even though these members were definitely working and aware of other topics of interest. The designers of the database were expecting the users to be capable of naming new topics. The interface was reviewed to "help" the user with this function. The changes required would utilize most of the remaining time available for updates in the database.

Thus the front end of the database was changed to take a user through a couple of screens that would "help" them name a topic. Once named, that topic would be compared to others in the database and the user would be prompted as to whether the topic was the same or different. From that point the user would be asked to either define the new topic or review the old topic and then rate either one using similar web pages as before.

Because of these changes, one of the key areas that one of the authors had wanted implemented prior to the TAC Workshop was not addressed, that is the hierarchical relationships between topics. The lack of this capability led to an initial flat database with nearly 500 topics with no way to establish relationships. We will describe one approach to this deficiency later in this paper. 


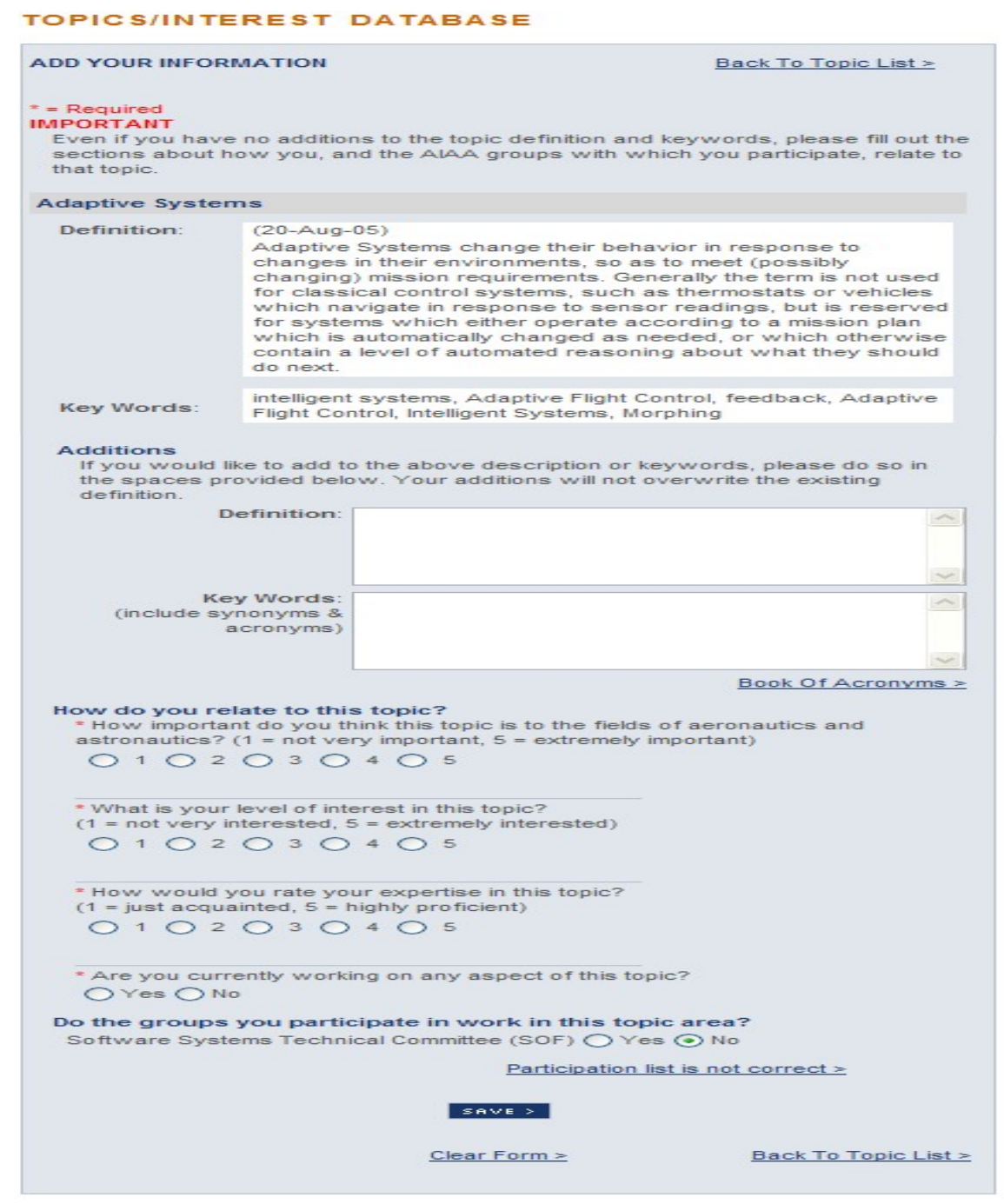

Figure 9. Augmenting Topic Definitions and Keywords

\section{O. AIAA Development - Topic Entry}

As described earlier, the Software Systems and Computer Systems TCs initially had difficulty understanding precise definitions of topics. Quad charts were used for this purpose providing pictures, diagrams, references and examples. With the number of TCs drastically increased, the issue of understanding and communicating meanings of topics emerged as one of the most significant. To resolve the conflicts or nuances that existed with how diverse TCs view, perceive and define topics, some capabilities were added to the tool, such as: the capability to add keywords, synonyms and acronyms as well as the capability to augment previously-defined topics. For instance, Figure 9 shows the definitions and keywords for the topic "adaptive systems." There are additional boxes that members may use to augment the previous definition or add to the list of previously-defined keywords. This additional capability helps to reduce the total number of topics and aids to bridge the gap between different definitions for the same topic as viewed between diverse TCs. 


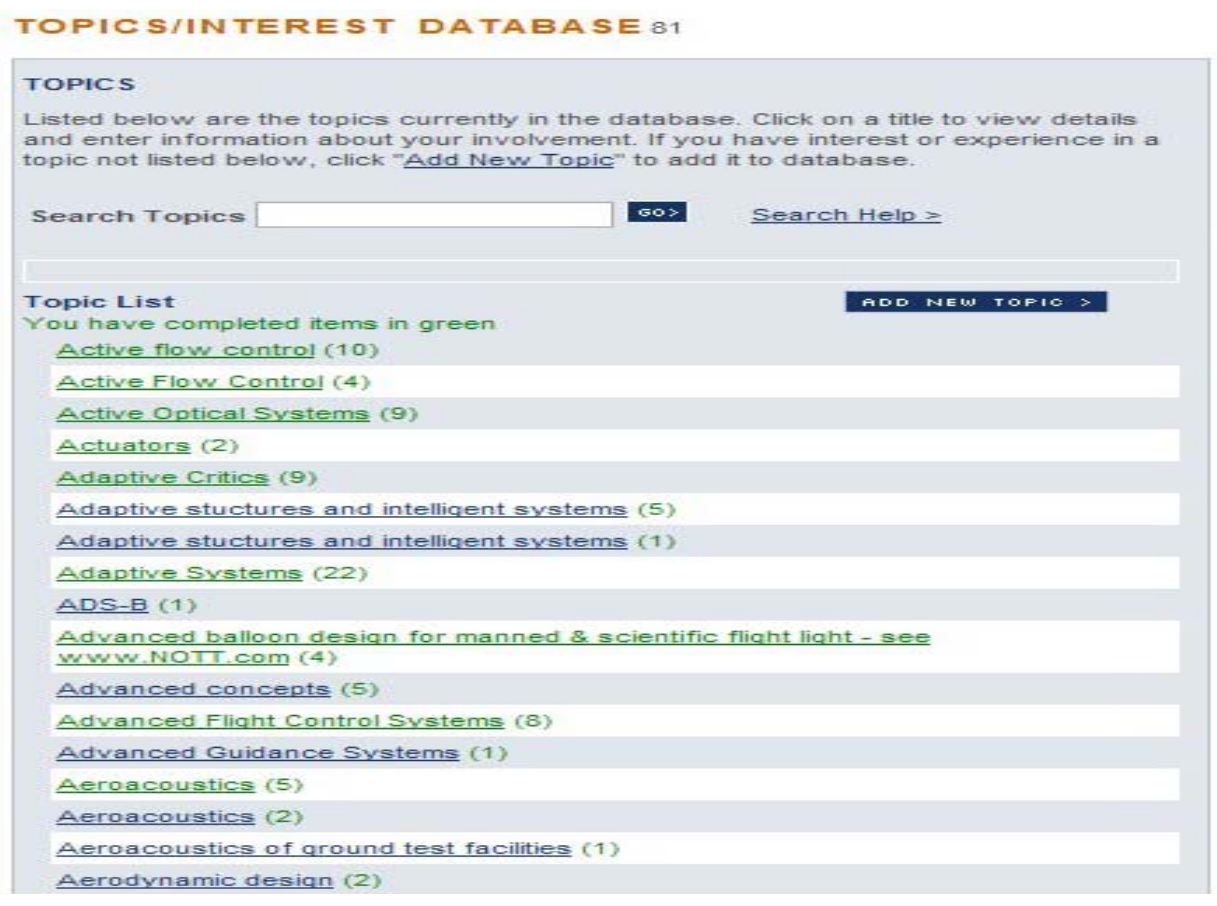

Figure 10. A Subset of Topics Listed Alphabetically

Figure 10 reveals a subset of the complete list of topics arranged alphabetically. As seen in Figure 10, there are a few topics that have significantly different meanings though they are called with the same title. The screen provides the capability to search for a specific topic as well as to add additional topics. The tool also has a logic that informs the user about topics that they've previously completed (in terms of their ratings of importance, interest and expertise) and identifies new topics inserted by other members (that the user has not yet rated). The number in parenthesis after each topic represents the number of members that have rated the particular topic.

\section{P. AIAA Development - Reports}

The topics database tool also provides insightful participation statistics with respect to the list of TCs or a member's specific TC. These statistics reveal the total number of TC members, the number of members that have utilized the tool, a percentage usage statistic and the number of members in a TC that have added new topics. The real benefit of the tool reveals itself with data reports, that is, the ability to identify the collective importance, interest and expertise of topics mapped to TCs and individuals. Using the Software Systems TC (SSTC) as an example, Figure 11 displays a partial subset of topics listed alphabetically. This can be viewed by selecting the group, Information Systems, and then selecting the committee name, Software Systems. By selecting the link for average importance (Avg Imp), the topics are now arranged to rank the most important topics as described by SSTC members (see Figure 12). A different ranking can be viewed by selecting the average interest (Avg Int) link (Figure 13). From this view (Figure 13), it appears that SSTC members have significant interest in fault tolerance and unmanned aerial vehicles (UAVs) among others. By selecting the link for average expertise (Avg Exp), a user can 


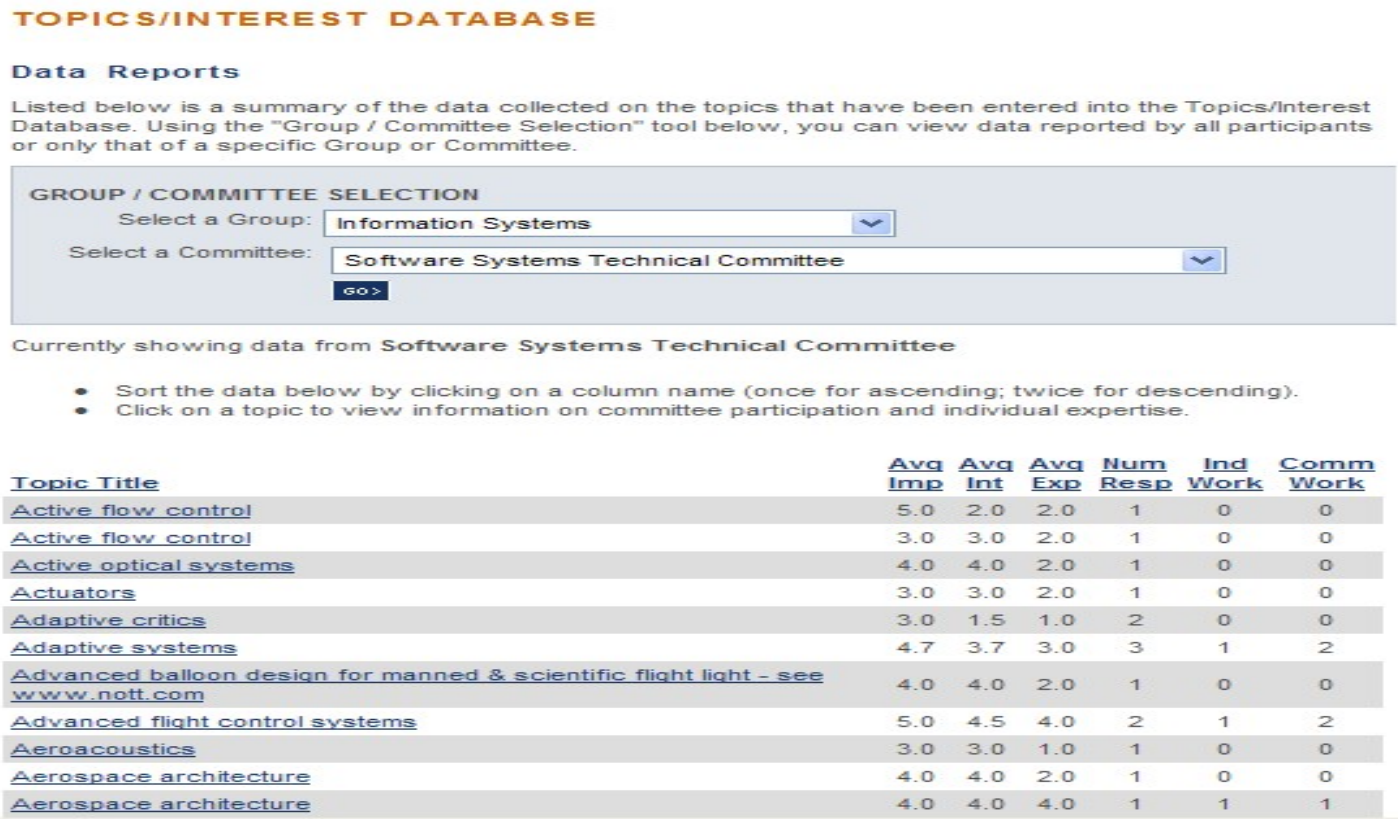

Figure 11. Software Systems TC Topics Listed Alphabetically

TOPICSIINTEREST DATABASE

Data Reports

Listed below is a summary of the data collected on the topics that have been entered into the Topics/lnterest Database. Using the "Group / Committee Selection" tool below, you can view data reported by all participants

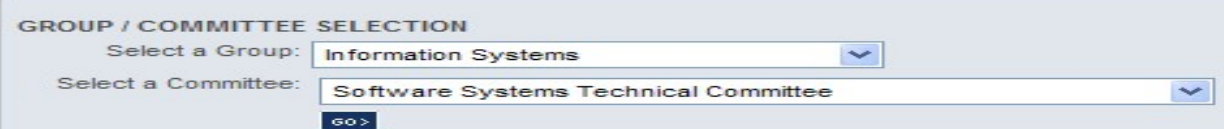

Currently showing data from Software Systems Technical Committee - Sort the data below by clicking on a column name (once for ascending; twice for descending).
- Click on a topic to view in formation on committee participation and individual expertise.

Topic Title

Confluence of commerical \& militarv/qovernment technologies Avq Avg Avq Num Ind Comm National aerospace system model

Real time systems

Fault tolerance

Information / computer security

Autonomy

Content-based information routing

Content-based information routing

Unmanned aerial vehicles

Liquid rocket test \& performance facilities and procesess

Active flow control

Operations research

Technology evaluation

Advanced flight control systems

Controls and health monitoring

Satellite communications

Aerospace meteorology (terrestrial and on-orbit environments)

Bavesian causal analysis

Space architecture

System/software development processes

Adaptive systems

Computer networks

Programminq lanquages

Models and simulation

\begin{tabular}{|cccccc} 
Imp & Int & Exp & Resp & Work & Work \\
\hline 5.0 & 4.3 & 4.3 & 3 & 3 & 2 \\
5.0 & 3.5 & 2.5 & 2 & 0 & 1 \\
5.0 & 4.2 & 3.6 & 5 & 4 & 3 \\
5.0 & 5.0 & 3.0 & 2 & 1 & 2 \\
5.0 & 4.3 & 3.3 & 3 & 2 & 1 \\
5.0 & 4.0 & 3.5 & 2 & 1 & 2 \\
5.0 & 4.0 & 3.0 & 1 & 0 & 0 \\
5.0 & 4.0 & 3.0 & 1 & 0 & 1 \\
\hline 5.0 & 5.0 & 4.0 & 1 & 1 & 1 \\
5.0 & 3.0 & 2.0 & 1 & 0 & 0 \\
5.0 & 2.0 & 2.0 & 1 & 0 & 0 \\
5.0 & 5.0 & 5.0 & 1 & 1 & 1 \\
\hline 5.0 & 5.0 & 4.0 & 1 & 1 & 1 \\
5.0 & 4.5 & 4.0 & 2 & 1 & 2 \\
5.0 & 5.0 & 4.0 & 1 & 1 & 1 \\
\hline 5.0 & 4.0 & 3.0 & 1 & 0 & 1 \\
5.0 & 5.0 & 2.0 & 1 & 0 & 0 \\
\hline 5.0 & 5.0 & 5.0 & 2 & 2 & 2 \\
\hline 5.0 & 5.0 & 4.5 & 2 & 2 & 2 \\
\hline 4.8 & 4.8 & 4.0 & 5 & 5 & 3 \\
\hline 4.7 & 3.7 & 3.0 & 3 & 1 & 2 \\
\hline 4.7 & 4.0 & 3.3 & 3 & 2 & 2 \\
\hline 4.7 & 4.3 & 4.0 & 3 & 2 & 2 \\
\hline 4.7 & 4.0 & 4.0 & 3 & 2 & 2 \\
\hline & & & & & \\
\hline
\end{tabular}

Figure 12. Software Systems TC Topics Ranking of Average Importance 
Data Reports

Listed below is a summary of the data collected on the topics that have been entered into the Topics/nterest Database. Using the -Group ' Committee Selectio
or only that of a specific Group or Committee.

\begin{tabular}{l} 
GROUP, COMMIT TEE SELECTION \\
Select a Group: Information Systems \\
Select a Committee: Software Systems Technical Committee \\
\hline So>
\end{tabular}

Currently showing data from Software Systems Technical Committee

Sort the data below by clicking on a column name (once for ascending; twice for descending)
Click on a topic to wiev information on committee participation and individual expertise.

Topic Title

Fault tolerance

Unmanned aerial vehicles

Operations research

Technology evaluation

Controls and health monitoring

Aerospace meteorology (terrestrial and on-orbit environments)

Bavesian causal anabrsis

Space architecture

Svstem/software development processes

Space environment

Advanced flight control systems

Tacsats, responsive spacecraft

Confluence of commerical \& militarv/qovernment technologies

Programming lanquages

Information / computer security

Cots hardware and software

Knowledge management

Open source for mission critical systems

Real time systems

Complex systems of systems

Nanotechnolgy applications to aerospace computing

Computer networks

Quantum computing and communication

\begin{tabular}{|c|c|c|c|c|c|}
\hline Avg & Ava & Ava & Num & Ind & comm \\
\hline & & & & & work \\
\hline 5.0 & 5.0 & 3.0 & 2 & 1 & 2 \\
\hline 5.0 & 5.0 & 4.0 & 1 & 1 & 1 \\
\hline 5.0 & 5.0 & 5.0 & 1 & 1 & 1 \\
\hline 5.0 & 5.0 & 4.0 & 1 & 1 & 1 \\
\hline 5.0 & 5.0 & 4.0 & 1 & 1 & 1 \\
\hline 5.0 & 5.0 & 2.0 & 1 & o & o \\
\hline 5.0 & s.o & s.o & 2 & 2 & 2 \\
\hline 5.0 & 5.0 & 4.5 & 2 & 2 & 2 \\
\hline 4.8 & 4.8 & 4.0 & 5 & 5 & 3 \\
\hline 4.5 & 4.5 & 2.5 & 2 & 0 & o \\
\hline 5.o & 4.5 & 4.0 & 2 & 1 & 2 \\
\hline 4.5 & 4.5 & 3.5 & 2 & 1 & 2 \\
\hline 5.0 & 4.3 & 4.3 & 3 & 3 & 2 \\
\hline 4.7 & 4.3 & 4.0 & 3 & 2 & 2 \\
\hline 5.0 & 4.3 & 3.3 & 3 & 2 & 1 \\
\hline 4.3 & 4.3 & 3.8 & 4 & 3 & 3 \\
\hline 4.5 & 4.3 & 3.3 & 4 & 3 & 2 \\
\hline 4.5 & 4.3 & 3.5 & 4 & 2 & 2 \\
\hline 5.0 & 4.2 & 3.6 & 5 & 4 & 3 \\
\hline 4.5 & 4.0 & 2.8 & 4 & 3 & 3 \\
\hline 3.5 & 4.0 & 2.0 & 2 & o & 1 \\
\hline 4.7 & 4.0 & 3.3 & 3 & 2 & 2 \\
\hline 3.0 & 4.0 & 2.0 & 2 & 0 & 1 \\
\hline
\end{tabular}

Figure 13. Software Systems TC Topics Ranking of Average Interest

TOPICSIINTEREST DATABASE

Data Reports

Listed below is a summary of the data collected on the topics that have been entered into the Topics/nterest Database. Using the -Group / Committee Selection
or only that of a specific Group or Committee.

GROUP / COMMITTEE SELECTION

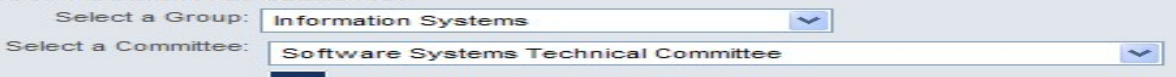

Sort the data below by clicking on a column name (once for ascending; twice for descending).
Click on a topic to wiev information on committee participation and individual expertise.

Iopic Title

Operations research

Bavesian causal analysis

Space architecture

Confluence of commerical \& military/qovernment technologies Plug and play

Programminq lanquages

Models and simulation

Svstemisoftware development processes

Unmanned aerial vehicles

Technology evaluation

Advanced flight control svstems

Controls and health monitoring

Aerospace architecture

Cots hardware and software

Real time svstems

Open source for mission critical systems

Open systems

Autonomy

Model-based reasoning

Tacsats, responsive spacecraft

Computer networks

Information/computer security

Technical evaluation of high performance computers and

\begin{tabular}{|c|c|c|c|c|c|}
\hline Avg & $\begin{array}{l}\text { Ava } \\
\text { int }\end{array}$ & $\begin{array}{l}\text { Ava } \\
\text { Exp }\end{array}$ & $\begin{array}{l}\text { Num } \\
\text { Resp }\end{array}$ & Ind & $\begin{array}{l}\text { Comm } \\
\text { work }\end{array}$ \\
\hline 5.0 & 5.0 & 5.0 & 1 & 1 & 1 \\
\hline 5.0 & 5.0 & 5.0 & 2 & 2 & 2 \\
\hline 5.0 & 5.0 & 4.5 & 2 & 2 & 2 \\
\hline 5.0 & 4.3 & 4.3 & 3 & 3 & 2 \\
\hline 4.0 & 4.0 & 4.3 & 3 & 2 & 1 \\
\hline 4.7 & 4.3 & 4.0 & 3 & 2 & 2 \\
\hline 4.7 & 4.0 & 4.0 & 3 & 2 & 2 \\
\hline 4.8 & 4.8 & 4.0 & 5 & 5 & 3 \\
\hline 5.0 & 5.0 & 4.0 & 1 & 1 & 1 \\
\hline 5.0 & 5.0 & 4.0 & 1 & 1 & 1 \\
\hline 5.0 & 4.5 & 4.0 & 2 & 1 & 2 \\
\hline 5.0 & 5.0 & 4.0 & 1 & 1 & 1 \\
\hline 4.0 & 4.0 & 4.0 & 1 & 1 & 1 \\
\hline 4.3 & 4.3 & 3.8 & 4 & 3 & 3 \\
\hline 5.0 & 4.2 & 3.6 & 5 & 4 & 3 \\
\hline 4.5 & 4.3 & 3.5 & 4 & 2 & 2 \\
\hline 3.5 & 4.0 & 3.5 & 4 & 2 & 2 \\
\hline 5.0 & 4.0 & 3.5 & 2 & 1 & 2 \\
\hline 4.5 & 4.0 & 3.5 & 2 & 1 & 0 \\
\hline 4.5 & 4.5 & 3.5 & 2 & 1 & 2 \\
\hline 4.7 & 4.0 & 3.3 & 3 & 2 & 2 \\
\hline 5.0 & 4.3 & 3.3 & 3 & 2 & 1 \\
\hline 43 & 33 & 33 & 3 & 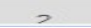 & 1 \\
\hline
\end{tabular}

Figure 14. Software Systems TC Topics Ranking of Average Expertise 
view ranked topics where the expertise resides within a particular TC (Figure 14). Additional links allow the user to determine if a TC has members who are currently working in the topic area as well as determining whether a particular committee is currently working in the topic area.

\section{TAC Workshop 2006}

\section{Q. Pre-Workshop Database Usage and Preparation}

Once the updated entry system was in place, a broad request went out to all AIAA TC Members to try the database, enter topics and help populate it. TC Chairmen were encouraged to get full member participation and they were given exclusive access to two reports which showed who had participated and more importantly who hadn't, along with emails and telephone numbers. Messages from AIAA came out every couple of days to encourage participation. Topic counts went from below 100 to over 600.

As the TAC workshop approached, the subcommittee and web developers worked together to put what was needed to hold the workshop in place. This mostly required the ability to display the data in the database in ways that the TC members could utilize. Scenarios for usage were revisited and a list of desired report types was created. A list of these report requirements is shown in Figure 15. Many of the reports described in the previous section were created in response to what was perceived as required for the workshop and all of the data requested in these requirements were actually realized in the reports.

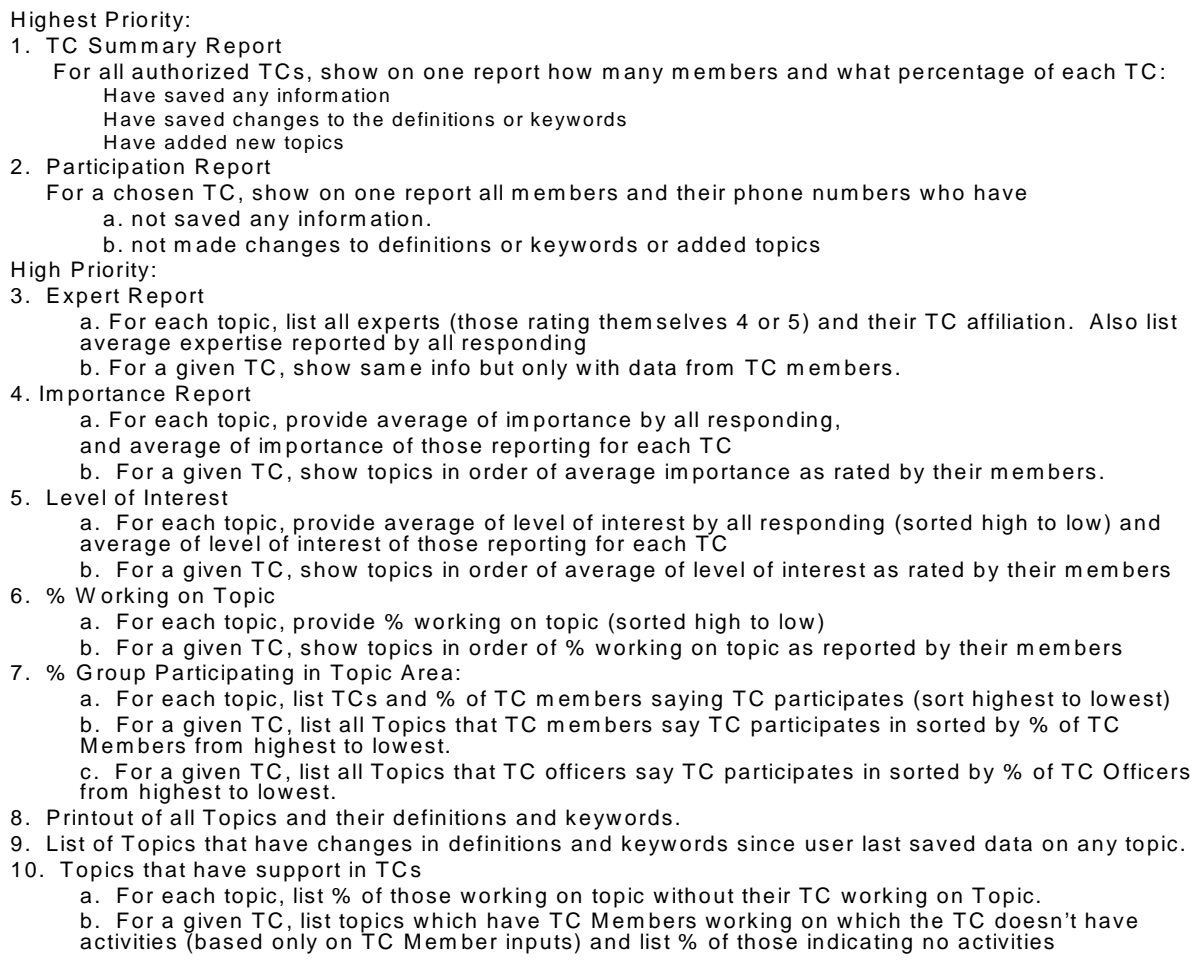

Figure 15. Report Requirements for TAC Workshop 




Figure 16. Potential Adaptation of Database for Creating Parent-Child Relationships

The agenda was worked during the week leading up to the workshop. There was significant discussion on how much time we had, how much we could expect a large diverse group to accomplish in an afternoon, how many would have access to a computer, and what was most important to get out of the workshop. During the final session, the process of setting the agenda and creating a dozen or so charts to be used at the workshop took over three hours to complete because a consensus was eventually reached.

At the workshop, the database was first introduced and the background for its creation explained. Then the goals for the workshop were relayed, namely that participants

1) Familiarize themselves with the Topics/Interest (T/I) Database

2) Brainstorm and report on innovative uses for the T/I Database

3) Develop a prioritized list of “next steps” for Database expansion

4) Discuss how the $T / I$ Database will be maintained

The workshop was divided into two parts - the first focused on the database and potential uses and the second focused on what to do next with it and how the database might be maintained. During each half, a short presentation would be given and then the participants would work individually or in small groups to navigate and use the database. Next, they worked in larger groups (tables of 8-12) to summarize what they learned, thought and discussed. These findings were then briefed back to the overall group. 
In an attempt to draw out new ideas, one of the slides shown was a concept for expanding the database to do parent-child relationships. This is shown in Figure 16. Here a combination of "P" and "C" buttons and a hierarchical display of those already related were used within the database structure to relate which topics were subsets or supersets of other topics.

\section{R. Results of the TAC Workshop and Benefits of the Topics/Interest Database}

The actual workshop was well-attended. AIAA arranged for a wireless access point within the conference room and thus anyone with a WIFI laptop could access the database live from the AIAA Website. This was marked as the first time an AIAA Website was accessed by so many within a single location.

There were eight tables of TC Leaders participating and all briefed charts on their experiences and discussions about the topics database, its use, future and maintenance. These charts were collected and briefed to the TAC. As a result of the out brief, it was decided to pursue the further expansion of the database, once a person could be identified to continue its evolution.

The following list identifies the current benefits of the Topics/Interest (T/I) Database grouped in two categories, communication and organizational structure:

I. Communication

a. Identifying and evolving the list of topic areas embodied by AIAA members

b. Establishing a shared understanding of the definitions of topics and relating these to keywords, synonyms and acronyms (as a means of establishing topic relationships)

c. Identify and map AIAA experts to AIAA aerospace topics

d. Identify topics deemed currently important to aerospace

e. Identify and map topics of interest to AIAA members

f. Identify AIAA members currently working in a topic area

g. Identify TCs currently working in a topic area

h. Identify emerging topics (can be mined by listing important aerospace topics with significant interest but with few if any experts)

i. Help TCs contribute meaningfully to Aerospace America articles (by filtering on activities in alignment with their topic areas)

j. Identify sets of TCs that should be consulted on Public Policy issues (can be mined by tracking topics related to issues and then mapping topics to various TCs)

II. Organizational Structure of the TCs/PCs

a. Determine the current degree of overlap between TCs (by making the scopes of TCs cleaner, that is little overlap, PC will have a better time determining which TC areas to include in PC membership)

i. Benefit: Guide new members towards synergistic committees based on areas of commonality 
ii. Benefit: Focus new membership drives toward area of high interest and low expertise

There were various concerns about the usability, the accuracy and the maintenance of the data collected. There were several new uses mentioned, and months after the workshop, the subcommittee members continue to be contacted for potential new uses of the database. There were new fields and relationships with other AIAA products identified. References and comparisons to the relatively new Wikipedia websites were drawn. No one wanted data monitoring to fall on a small number of TC leaders as TC leaders often felt overloaded with their current responsibilities. There was also a concern that mandatory use would produce poor quality inputs versus focusing on a good product that would attract good usage.

\section{Future Uses}

\section{S. Future Benefits Gained by Minor Extensions to the T/I Database}

Though the TCs will continue to exercise the current benefits of the Topics/Interest Database tool to aid its daily business activities, there are additional benefits that may be gained through extensions. These extensions or additions come in two flavors, minor and system-level. The following list of benefits describes a few examples that can be gained by minor extensions to the existing tool:

1. Conferences:

- Map clusters of topics to existing and new conferences

- Utilize interest and experience indicators to provide an AIAA Conference Guide Tool

2. Modify the organizational structure of TCs/PCs from a bottom-up perspective (to minimize overlap)

3. AIAA Journals:

- Map clusters of topics to existing and new journals

- Utilize interest and experience indicators to provide an AIAA Journal Guide Tool

4. Identify and Map the Relationships/Interdependencies between Aerospace Topics (can be used as a predictive tool to identify most likely effects of policy changes, new technologies, topic obsolescence, etc.)

5. AIAA Standards/Books/Courses/Awards:

- Map clusters of topics to existing Standards/Books/Courses/Awards

- Utilize interest and experience indicators to provide a Guidance Tool for Standards/Books/Courses/Awards

\section{T. Future Benefits Gained by System-Level Extensions to the T/I Database}

TAC and other larger committees generally operate from a systems-perspective. They desire to identify and solve problems somewhat different from individual TCs. The Topics/Interest Database tool can aid this systemlevel insight and analysis as well with additional, perhaps, significant work. At least two system-level benefits were envisioned with extensions to the current tool that may provide benefits that do not currently exist in any technical organization or technical society. 
1. (Historical Topic Development) Develop a dynamically-clustered dependency model between topics to aid the Aerospace community identify the impact and interactions of topics over time.

- Benefit: This system-level addition may be helpful for CNN or the History Channel when they want the history of a topic describing all the major impact to a topic over time.

2. (Topic Impacts to Daily Life) Develop a layman's perspective of an aerospace topic to show how TCs influence the development and evolution of aerospace technology areas.

- Benefit: This system-level addition may aid John/Jane Doe understand how AIAA impacts and influences a topic from which they currently benefit in their daily life.

Even without minor or system-level extensions, the current Topics/Interest (T/I) Database tool provides significant insight into the true currency that flows from all TC products and events, namely, aerospace topics. These topics are born with new technology, evolve based on policies, competition, standards, and then become obsolete over time. It is a wise investment for AIAA to identify and capture the lifeblood of technical committees and support a means by which the daily business of TCs becomes easier and tractable. The Topics/Interest Database tool provides a beneficial decision aid for TCs as they collectively make the AIAA the principal voice devoted to global leadership in the aerospace community.

\section{Acknowledgements}

The Computer Systems and Software Systems Technical Committees owe a significant amount of gratitude to the individual members that contributed to the original TC quad charts and ratings spreadsheets. We would like to give a special thank you to Jim Neidhoefer for recognizing and identifying the benefit of our initial tool to the larger AIAA audience and for introducing and championing the larger concept to and through the New Initiatives Subcommittee and its parent organization, the Emerging Technologies Committee. We thank Jim for his efforts in conveying the purpose and benefits of the tool and spearheading its debut at the TAC Leadership Workshop. We would also like to thank AIAA web staff including Sean Malone and Sharon Smith for implementing the topics database on the AIAA Website along with its TCs and PCs for helping us develop, populate and evolve our initial tool to what it is today. It is our sincere desire that AIAA utilizes this tool (or some variant) for the benefit of the members.

\section{References}

[1] The Topics/Interest Database can be accessed via the main AIAA homepage: http://www.aiaa.org/.

\footnotetext{
${ }^{1}$ TAC Workshop Presentation to TAC, J. Neidhoefer, June 17, 2005.
} 